\title{
Evaluation and Comparison of DC-DC Power Converter Variations in Solar Panel Systems Using Maximum Power Point Tracking (MPPT) Flower Pollination Algorithm (FPA) Control
}

\author{
Mohammad Luthfansyah ${ }^{1, *}$, Suyanto Suyanto ${ }^{1}$, and Abu Bakarr Momodu Bangura ${ }^{2}$ \\ ${ }^{1}$ Department of Engineering Physics, Institut Teknologi Sepuluh Nopember, Jl. Teknik Kimia, \\ Surabaya, East Java, 60111 Indonesia \\ ${ }^{2}$ Physics \& Mathematics, Fourah Bay College, University of Sierra Leone, 17 British Council Road, \\ Freetown, Sierra Leone
}

\begin{abstract}
Maximum Power Point Tracking (MPPT) is a method that can be used to optimize the electrical power output from solar panels. The performance of the MPPT method on solar panel systems can be influenced by many variables. One of them is the selection of a DC-DC power converter. DC-DC-DC Converter is a component that is used to optimize the performance of solar panels. Several types of DC-DC Converter are Buck, Buck-Boost, Single Ended Primary Inductance Converter (SEPIC), and CUK. Each converter has a different effect on solar panels output power. In order to observe and make a comprehensive analysis, simulations are performed through PSIM (Power Simulator) software on the performance of several DC-DC Converters that use Flower Pollination Algorithm (FPA) as the MPPT algorithm. Variables that observed are the output power characteristic, the response of the voltage-current ripple signal, and the accuracy of the converter in the process of reaching the maximum power point condition. As a result, CUK converter can obtain the highest value of solar panel output power, $145.02 \mathrm{~W}$. A low ripple level with a stable power value response is entirely generated by CUK and SEPIC Converter. Overall, for this system, the CUK converter has better performance than the other converters.
\end{abstract}

Keywords: Buck converter, buck-boost converter, cuk converter, dc-dc converter comparison, single-ended primary inductance converter.

\section{Introduction}

The solar panel system has been widely used in various ways, especially in the realm of renewable energy sector power generation. The solar panel system cannot run alone. It needs several supporting components so that the system runs well. One component that highly supports and improves the performance of solar panel systems is DC-DC converter. Elaborating on previous research, DC-DC Converter can increase the electrical output of solar panels no less than $5 \%$ compared to the system without DC-DC Converter $[1,2]$. DC-DC Converter is a type of power converter that can be used to set the output voltage parameters to the input voltage. The basic working principle of a power converter lies in

*Corresponding author: luthfan48@gmail.com 
switching and the accuracy of the values of the components. DC-DC Converter is widely applied to large systems or as sub-systems with source and output systems in the form of DC electrical networks [3]. DC-DC Converter can be applied one of them on a power generation system with a source of solar panels. Some of the objectives of implementing DC-DC converter on solar panel electrical networks such as: optimizing the output of solar panel power, maintaining the output voltage of solar panels at a certain value range, or for other system applications [4, 5]. Some examples of DC-DC Converter are Buck Converter, Boost Converter, Buck-Boost Converter, SEPIC Converter, CUK Converter, ZETA Converter, and other types of DC-DC Converter [6]. This research is intended to find out what type of converter has the best performance in solar panel optimization systems.

\section{Overall system design}

In this study, DC-DC Converter has a critical function in influencing the electrical parameters of solar panels. The converter will be connected between solar panels and the electrical load. The main function of the converter is to find the best duty cycle value so that the electrical output of the solar panel will be in its optimal position. All converters are designed using the same frequency value and average component ripple design. The current and voltage value for both the input and output sides of the converter is also designed precisely the same.

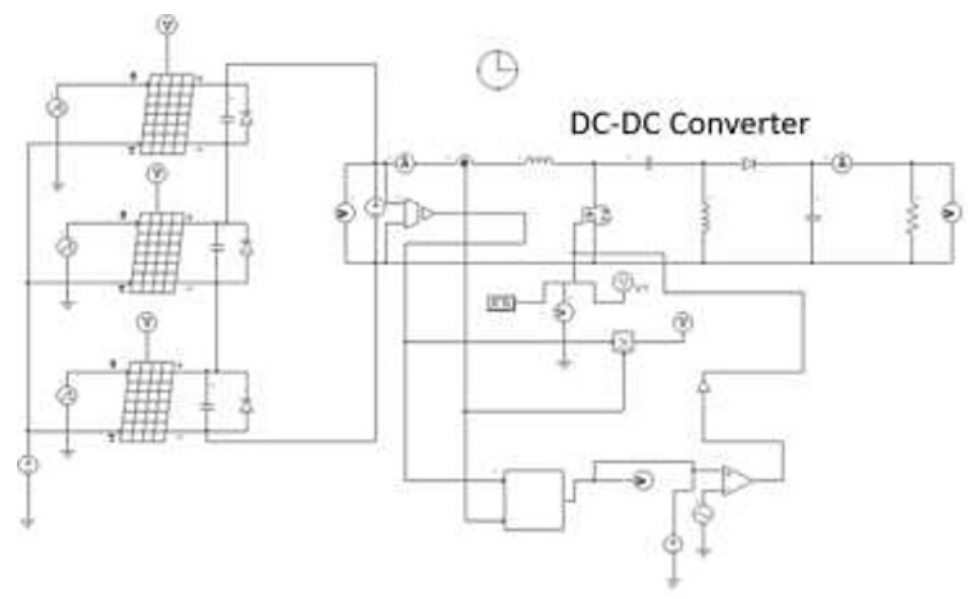

Fig. 1. Main system and DC-DC Converter configuration.

Table 1. Converter's components design.

\begin{tabular}{|c|c|c|c|c|c|c|c|c|c|c|}
\hline Converter & $\mathbf{D}$ & $\Delta \mathbf{I}_{\mathbf{L} 1}$ & $\Delta \mathbf{I}_{\mathbf{L} 2}$ & $\begin{array}{c}\mathbf{L}_{\mathbf{1}} \\
(\mathbf{H})\end{array}$ & $\mathbf{L}_{\mathbf{2}}(\mathbf{H})$ & $\mathbf{C}_{\mathbf{1}}(\mathbf{F})$ & $\mathbf{C}_{\mathbf{2}}(\mathbf{F})$ & $\Delta \mathbf{V}_{\mathbf{C} \mathbf{1}}$ & $\Delta \mathbf{V}_{\mathbf{C} 2}$ & $\mathbf{R}(\mathbf{\Omega})$ \\
\hline Buck & 0.82 & 0.6 & - & $0.38 \mathrm{~m}$ & - & $42.42 \mu$ & - & 0.0442 & - & 14.73 \\
\hline $\begin{array}{c}\text { Buck- } \\
\text { boost }\end{array}$ & 0.452 & 1.096 & - & $1.2 \mathrm{~m}$ & - & $768.4 \mu$ & - & 0.0442 & - & 14.73 \\
\hline CUK & 0.452 & 0.562 & 0.6 & $1.07 \mathrm{~m}$ & $1.007 \mathrm{~m}$ & $369.2 \mu$ & $8.484 \mu$ & 0.092 & 0.092 & 14.73 \\
\hline SEPIC & 0.452 & 0.562 & 0.562 & $1.07 \mathrm{~m}$ & $1.07 \mathrm{~m}$ & $768.4 \mu$ & $768.4 \mu$ & 0.0442 & 0.0442 & 14.73 \\
\hline
\end{tabular}

The condition of solar panels is also regulated according to the standard test condition (STC), which is solar irradiation of $1000 \mathrm{~W} \mathrm{~m}{ }^{-2}$ with a stable temperature of $25^{\circ} \mathrm{C}$. The 
whole system will be simulated using PSIM (Power Simulator) software to reduce the number of errors and get ideal performance.

\subsection{Maximum power point tracking (MPPT)}

Solar irradiation changes very often. Exposure to sunlight that is not constant in one day makes the solar panel system must be able to adapt. The power output of the solar panel must always be at a maximum point when it is below any irradiation value [7]. MPPT is a method that can be used in finding the optimal point of power output from solar panels [8]. This method is usually applied, accompanied by an optimization algorithm to speed up the discovery of the highest power value. The key to MPPT is to change the duty cycle value in the DC-DC Converter switching system.

\subsection{Flower pollination algorithm (FPA)}

The algorithm in the form of artificial intelligence is adapted from the characteristics of pollinating flowers by insects in general. Conceptually, insects will continue to move from one flower to another until the best flower is obtained. The basic FPA equation uses the Himmelblau function. The algorithm was made by Xie Yang in 2012. FPA is one algorithm that can be used to make the best decision in an optimization problem. The MPPT case is an example of an optimization problem that can be solved by the FPA algorithm [9].

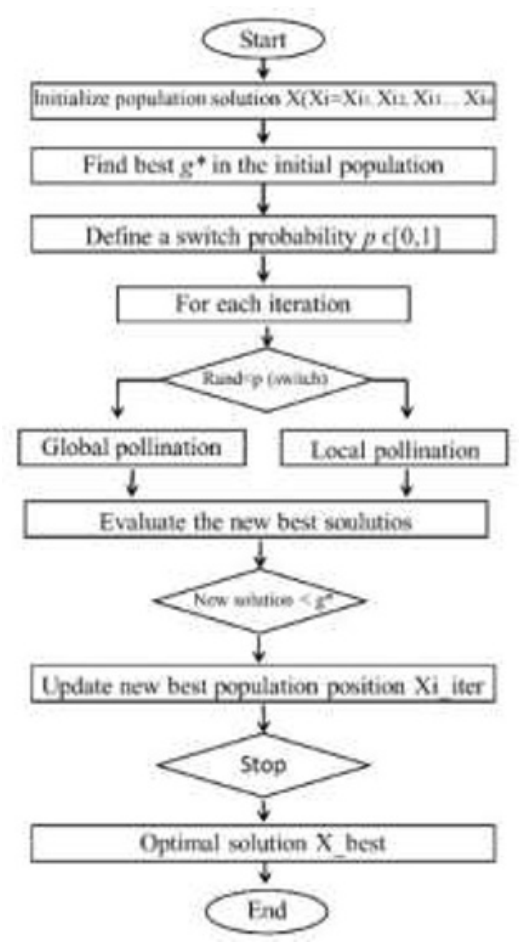

Fig. 2. Flower pollination algorithm (FPA) flowchart. 
In the case of MPPT, the FPA will continue to look for the best duty cycle value by comparing the output power before and after it. This process will continue to be done by changing little by little the constant FPA equation, which will have an impact on changing the converter duty cycle value. The algorithm will completely stop working when the power value has reached its maximum point, or when the duration of the processing time has reached its limit.

\subsection{Buck converter}

Buck Converter is a power converter that functions to reduce the voltage. Buck Converter consists of a series of basic converters with the addition of a low pass filter circuit [10]. Some examples of using Buck Converter are to set the speed of a DC motor. Buck Converter is called a step-down converter because the output voltage does not exceed the input voltage of the converter. Elaborating on previous research, it is found that Buck Converter has a performance with an efficiency of not less than 95\% [1]. As shown in the Buck Converter circuit in Figure 3 part (a), the switch is installed in series.

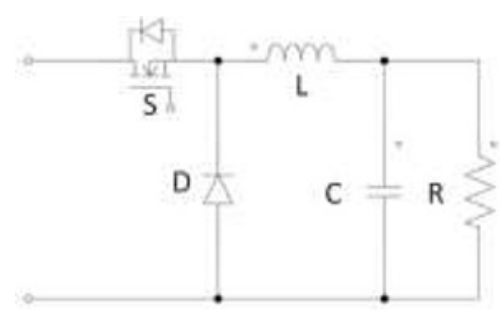

(a)

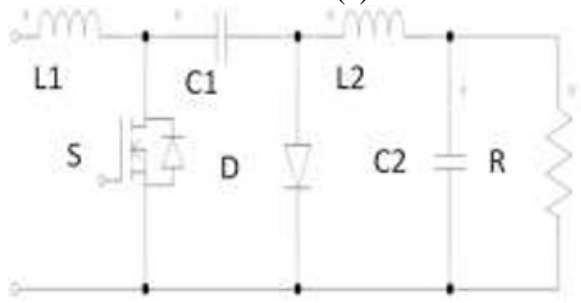

(c)

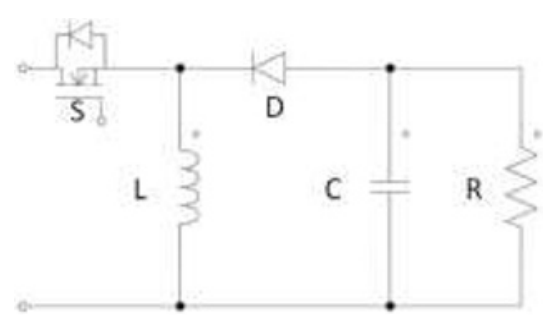

(b)

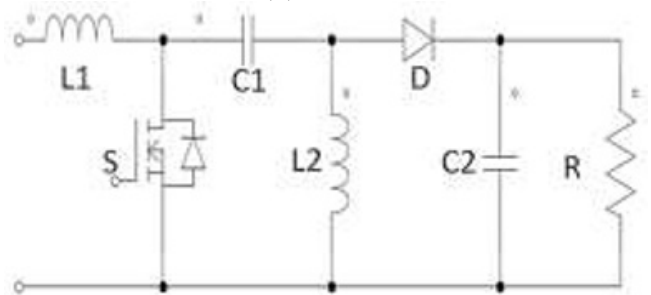

(d)

Fig. 3. DC-DC Converter electric circuit of (a) Buck converter; (b) Buck-Boost converter; (c) CUK converter; and (d) SEPIC converter.

\subsection{Buck-Boost converter}

This type of power converter can function as a Buck Converter and Boost converter. So this converter has the ability to decrease or increase the output voltage. Therefore the converter output voltage can be smaller or greater than the input voltage of the converter. The BuckBoost Converter's output voltage has an inverse polarity and can be of greater or lesser value than the input voltage. In some tests, the performance efficiency of Buck-Boost Converter is not less than $95 \%$ for changes in the duty cycle. Figure 3(b) shows if BuckBoost Converter is a type of converter that has a switch connected in series. In previous research results, obtained if the Buck-Boost Converter efficiency is not less than $96.5 \%$ [11]. 


\subsection{CUK converter}

CUK is a type of electrical converter that has nearly the same characteristics as the characteristics of the Buck-Boost Converter. The main characteristic of CUK, is the reverse polarity of the voltage at the output side of the converter, as in the Buck-Boost converter. In addition to polarity, the similarity of the CUK Converter with Buck-Boost is its function, which is able to make the converter output voltage larger or smaller with respect to the input side voltage, electricity. Elaborating on the results of previous studies, obtained if the efficiency of the performance of the CUK Converter is not less than $90 \%$ [2]. The schematic of the CUK Converter can be seen in Figure 3(c), with the switch attached in parallel.

\subsection{SEPIC converter}

Single Ended Primary Inductance Converter (SEPIC) is a type of converter with almost the same capabilities as Buck-Boost Converter or CUK Converter. This type of converter is used to supply load modules, which tend to have a higher voltage rating [5]. Basically, the mathematical equation that applies to SEPIC Converter is also almost the same as the mathematical equation that applies to Buck-Boost Converter and CUK Converter. The main difference between SEPIC Converter and Buck-Boost or CUK type converters is the nonreversal voltage polarity on the output side of the converter. In the results of previous studies, the SEPIC Converter has a performance with efficiency, not less than $88 \%$ [12]. The SEPIC Converter schematic can be seen in Figure 3(d), with the condition of the circuit switches attached in parallel.

\section{Simulation result}

DC-DC Converter is simulated, as shown in Figure 1, and using the adjusted component value parameters in Table 1. Based on the test response, Buck Converter succeeded in optimizing the output power of the solar panel by $124.24 \mathrm{~W}$ with the time needed for $0.0079 \mathrm{~s}$. Buck-Boost Converter can optimally optimize the electrical power output of $76.69 \mathrm{~W}$ in $0.0237 \mathrm{~s}$. CUK Converter is able to reach $145.02 \mathrm{~W}$ with a time required of $0.07 \mathrm{~s}$. The SEPIC Converter succeeded in making the solar panel produce electrical power of 144.41 with a convergence of time required of $0.072 \mathrm{~s}$.

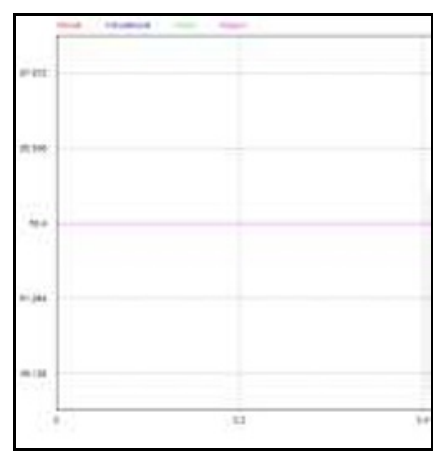

(a)

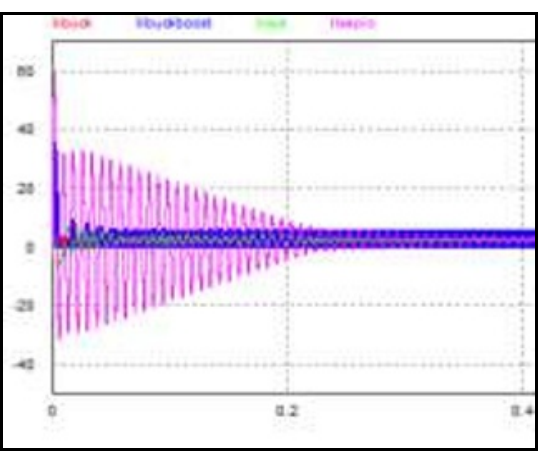

(b) 


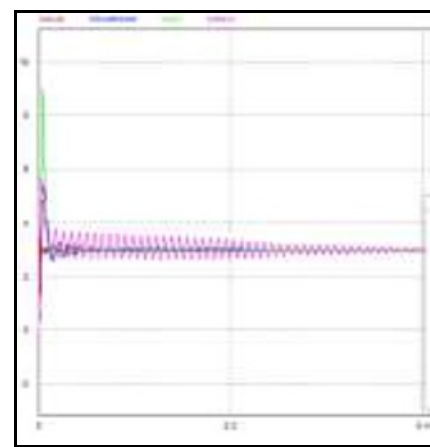

(c)

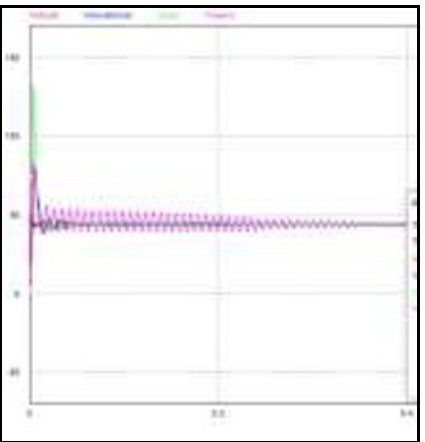

(d)

Fig. 4. Partial test results of DC-DC Converter with Buck (red), Buck-Boost (blue), CUK (green), and SEPIC (purple): (a) voltage input; (b) current input; (c) voltage output; and (d) current output.

\section{Analysis}

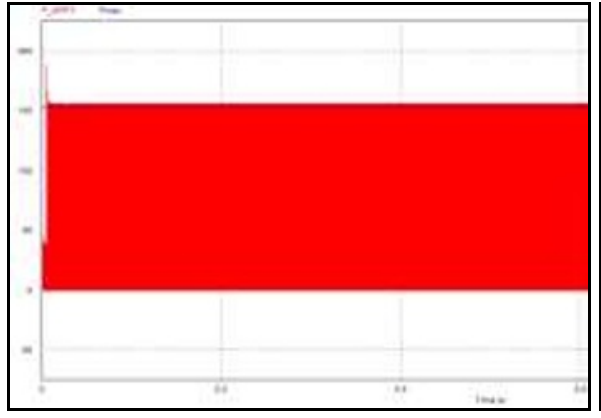

(a)

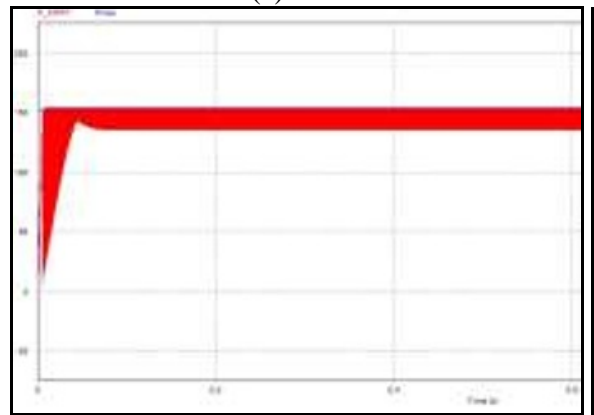

(c)

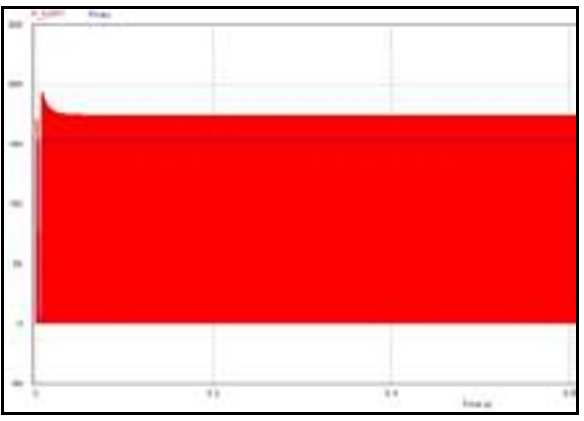

(b)

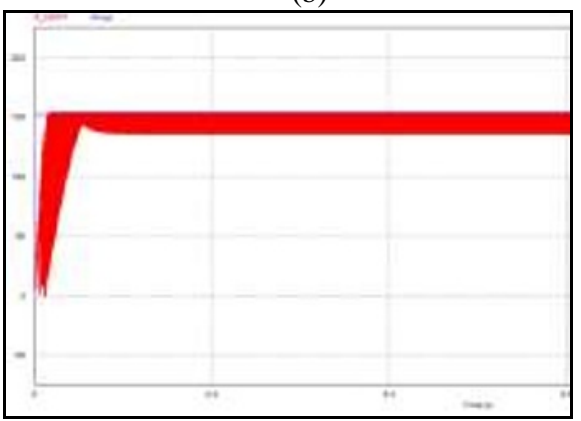

(d)

Fig. 5 Solar panel power output responds after connected with (a) Buck Converter; (b) Buck-Boost Converter (current and voltage colour reversed); (c) CUK Converter; and (d) SEPIC Converter. 


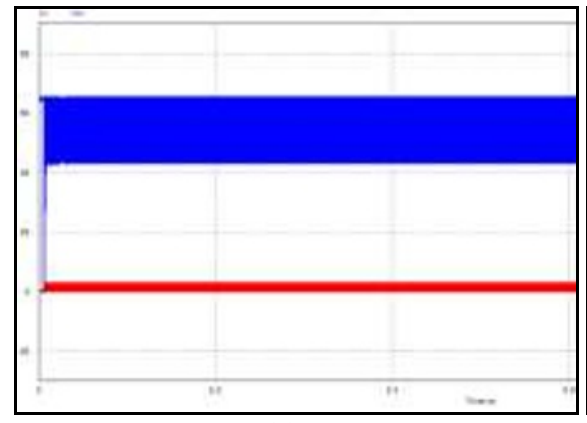

(a)

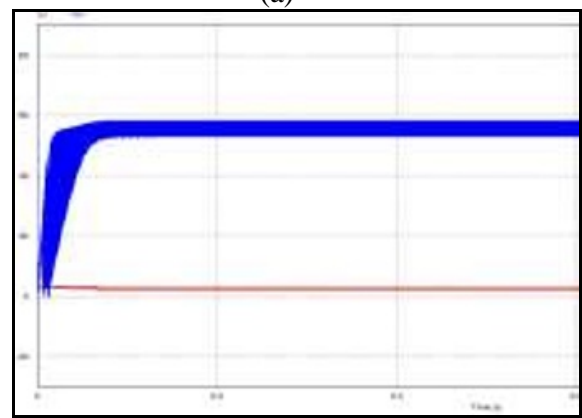

(c)

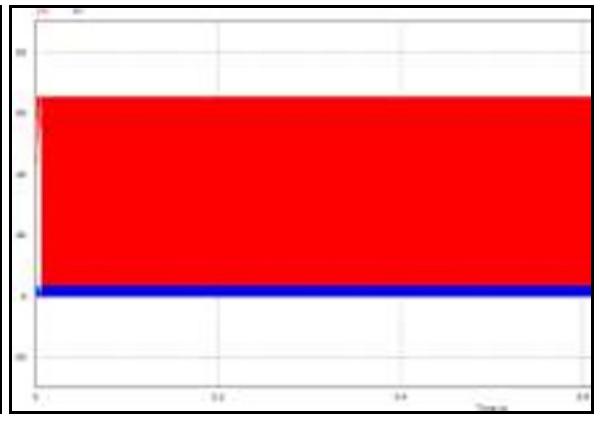

(b)

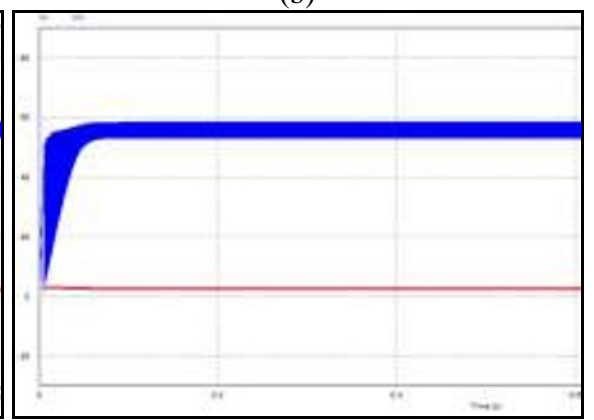

(d)

Fig. 6. Solar panel current (red) and voltage (blue) output respond from (a) Buck Converter, (b) Buck-Boost Converter (the current and voltage colour are reversed), (c) CUK Converter, and (d) SEPIC Converter.

In the initial condition, the converter is tested partially without solar panel or control. Table 2 indicates that the efficiency performance of the converter, before being connected to the main system, it has been in good condition. After knowing the converter's ideal efficiency, a test is performed by connecting the converter to the central system (solar panels and control circuit). Based on the simulation results, it is found that the CUK Converter is a converter with the best MPPT accuracy with an optimization result of 145.02 $\mathrm{W}$ over other types of converters. In general, the optimization of solar panel power by CUK and SEPIC converters is still better than Buck and Buck-Boost converters. One reason is the presence of two inductors and two capacitors working in the CUK and SEPIC converters. With the presence of more inductors and capacitors than the number of inductors and capacitors for Buck or Buck-Boost converters, energy storage in CUK and SEPIC converters is more effective and stable. In addition, converters with parallel switches such as CUK and SEPIC do not have large ripple current and voltage. It is different from converters that have a series link switch, where there is a large ripple on the current and voltage. 
Table 2. Converter performance result

\begin{tabular}{|c|c|c|c|c|c|c|}
\hline Converter & $\begin{array}{c}\text { Efficiency } \\
(\%)\end{array}$ & $\begin{array}{c}\text { Vmppt } \\
(\mathbf{V})\end{array}$ & $\begin{array}{c}\text { Imppt } \\
(\mathbf{A})\end{array}$ & Pmppt (W) & $\begin{array}{c}\text { ConvT } \\
(\mathbf{S})\end{array}$ & Ripple \\
\hline Buck & 99.85 & 53.696 & 2.422 & 124.24 & 0.0079 & Big \\
\hline $\begin{array}{c}\text { Buck- } \\
\text { Boost }\end{array}$ & 99.064 & 48.089 & 1.597 & 76.799 & 0.0237 & Big \\
\hline CUK & 97.07 & 55.57 & 2.61 & 145.02 & 0.07 & Small \\
\hline SEPIC & 97.24 & 55.103 & 2.63 & 144.41 & 0.072 & Small \\
\hline
\end{tabular}

\section{Conclusion}

In general, each converter has worked well until the maximum power point value is obtained. The low optimization results of several converters are caused by the ripple that occurs, especially in Buck and Buck-Boost type converters. The amount of the ripple value interferes with the sensor reading process, which then becomes input data from the FPA algorithm. To reduce performance degradation due to ripple, the converter can be connected to the snubber circuit.

\section{References}

1. N.A. Windarko, A. Tjahjono, D.O. Anggriawan, M.H. Purnomo, Maximum power point tracking of photovoltaic system using adaptive modified firefly algorithm. International Electronics Symposium, (Surabaya, Indonesia, 2015) IEEE, 31-35(2016). https://ieeexplore.ieee.org/document/7380809.

2. L. Mohammad, E. Prasetyono, F.D. Murdianto, Performance evaluation of ACO-MPPT and constant voltage method for street lighting charging system. Paper Presented in International Seminar on Application for Technology of Information and Communication (Semarang, Indonesia, 2019). https://ieeexplore.ieee.org/document/8884303.

3. V.M. Phap, N. Yamamura, M. Ishida, J. Hirai, N.T. Nga, Design of novel grid-Tied solar-Wind hybrid power plant using photovoltaic cell emulating system, International Conference on Sustainable Energy Technologies (ICSET) (Hanoi, Vietnam, 2016) IEEE, 1:186-189(2017). https://ieeexplore.iee.org/document/7811779

4. A.J. Hanson, C.A. Deline, S.M. MacAlpine, J.T. Stauth, C.R. Sullivan, IEEE J. Photovoltaics, 4,6:1618-1624(2014).

https://ieeexplore.ieee.org/abstract/document/6892936/

5. A. Akila, E. Akila, S. Akila, K. Anu, J. Elzalet, Charging station for e-vehicle using solar with IOT, The 5th International Conference on Advanced Computing and Communication Systems (ICACCS) (Tamil Nadu, India, 2019) IEEE, 785-791(2019). https://ieeexplore.ieee.org/document/8728391

6. D.W. Hart, Power electronic. New York: McGraw-Hill (2011). p. 496. https://www.academia.edu/32772671/Power_Electronics_Daniel_W. Hart

7. V.R. Kota, M.N. Bhukya, IET Renew. Power Gener., 13,10:1647-1659(2019). https://ieeexplore.ieee.org/document/8759813

8. F. Wang, R. Gou, T. Zhu, Y. Yang, F. Zhuo, Comparison of DMPPT PV system with different topologies, 2016 China International Conference on Electricity Distribution (CICED) (Xi'an, China. 2016). IEEE, 1-5(2016), https://ieeexplore.iee.org/document/7576359. 
9. S. Suyanto, L. Mohammad, I.C. Setiadi, R. Roekmono, Analysis and evaluation performance of MPPT algorithms: Perturb observe (PO), firefly, and flower pollination (FPA) in smart microgrid solar panel systems. International Conference on Technologies and Policies in Electric Power and Energy (Yogyakarta, Indonesia, 2019). IEEE, 1-6(2019). https://ieeexplore.ieee.org/document/9102532

10. S. Saha, A. Bhattacharjee, D. Elangovan, G. Arunkumar, "DC microgrid system for rural electrification," International Conference on Energy, Communication, Data Analytics and Soft Computing (ICECDS) (Chennai, India, 2017). IEEE, 307313(2018), https://ieeexplore.ieee.org/abstract/document/8390006 .

11. M. Neethu, R. Senthilkumar, Soft computing based MPPT controller for solar powered battery charger under partial shading conditions, The 5th International Conference on Electrical Energy Systems (ICEES) (Chennai, India, 2019). IEEE, 1-6(2019). https://ieeexplore.ieee.org/document/8719314

12. S. Ilayaraja, T.V. Narmadha, Modeling of an e-vehicle charging station using DC-DC self-lift SEPIC converter, 2016 Second International Conference on Science Technology Engineering and Management (ICONSTEM) (Chennai, India, 2016). IEEE, 526531(2016). https://ieeexplore.ieee.org/document/7560949 